\title{
A Brief Talk on Practical Teaching Reform of Higher Vocational E-commerce Major Based on Internet Plus Background
}

\author{
Ning Chi \\ Department of Information \& Technical \\ Wenzhou Vocational \& Technical College \\ Zhejiang, China \\ 30935317@qq.com
}

\begin{abstract}
There are still many problems in the practical teaching of the e-commerce major in the higher vocational colleges under the internet plus background. Colleges need to clarify the goal of talent training and develop a scientific and standardized plan for practical training. Colleges will concentrate resources on various aspects and provide students with practical training and learning environment, mobilizing all forces to match teaching with the actual market environment and enhance the effectiveness of teaching. What's more, colleges will implement professional teaching. Theory and practice should be fully combined to enhance the market competitiveness of higher vocational students.
\end{abstract}

Keywords-Internet Plus; E-commerce major in higher vocational education; Practical training; Reform

\section{INTRODUCTION}

The development of Internet technology has enabled ecommerce to flourish more than ever before. This has also prompted higher vocational colleges to become the current hot professional. Higher vocational teaching advocates the orientation of professional training, and pays attention to the cultivation of the professional ability of talents. Faced with the current Internet plus environment, in the professional training of higher vocational e-commerce professionals need to pay attention to the promotion of practical training, so as to enhance the actual operation ability, so that the theory and practice full integration, improve the ultimate effectiveness of education.

\section{PRACTICAL TEACHING OF Higher VocAtional E-} COMMERCE MAJOR IN THE INTERNET PLUS BACKGROUND

\section{A. The goal of personnel training is not clear}

The current lack of a clear and explicit talent training plan in the practical teaching of higher vocational e-commerce professional education, the content of the training is more elementary, and the actual market demand for high-quality talent can not be effectively satisfied. The laws governing the demand for talents in the market lack good expectations and planning, which leads to lagging behind in the cultivation of talents and the actual market environment. In terms of more training, teachers themselves lack sufficient social work experience, and even a lot of teachers follow the textbooks. Although they can understand the characteristics and basic conditions of e-commerce under the Internet environment, they cannot develop the ability to solve students' practical problems. Especially in the e-commerce work environment, the face of the Internet environment is changing rapidly, and the development of teaching theory often lags behind the changes in the actual market environment. Therefore, although the professional training of talents is market-oriented, there is a certain gap between the actual refined demand of the market. More talent knowledge has cultivated entry-level basic capabilities, and lack of effective analysis, observation, and application capabilities for practical use. Although some schools carry out school-enterprise cooperation, the choice of school-enterprise cooperation is not ideal enough to achieve real value of school-enterprise cooperation. Enterprises lack support for teaching and teaching methods have not been innovatively developed. In terms of personnel training, there is no actual practice based on actual teacher resources, the school's hardware environment, and student characteristics, and it lacks the cultivation of specialization. The talent training lacks the spirit of adapting to local conditions and there is no scientific and sound planning and training process and methods

\section{B. Simulation software can not effectively train combat capabilities}

In e-commerce teaching, a variety of simulation software is used to simulate the real operating environment, but there are still great differences from the actual operating environment Actual e-commerce encounters a variety of problems. At the same time, this kind of problem will emerge in an endless stream and will continue to change as society changes. Past problems need to be dealt with, but it does not mean that past experience can solve the current situation. The design of the simulation software itself has limitations and lags, and the intelligence meets the basic knowledge application ability simulation, which cannot be effectively dealt with for updating more complex problems. Excessive trust simulation software ignores actual combat training arrangements. In the simulation software, there is a lack of actual participation of the actual 
enterprise, and the situation has an original setting template. However, this setting does not necessarily meet the varied and varied actual conditions, and even a student may become aware of the fixed mode and fall into a single operation. In the sense of learning, we cannot effectively adapt to actual social changes. For example, in the "E-Commerce Fundamentals" course, we purchased a company's e-commerce basic training simulation software. The software simulation is the Alibaba's B2B, B2C, C2C and other platform operations. However, the rules of the Alibaba platform have been changing, and the simulation software has been unable to keep up with the rhythm. Therefore, for students, the significance of training through this software is very limited.

\section{Insufficient teachers}

In terms of faculty resources, many teachers belong to theoretical studies and have professional accumulation at the theoretical level. However, they lack the knowledge and ability to deal with practical problems. In particular, many higher vocational teachers belong to academic research and lack the practical application skills in the actual enterprises. They cannot fully and effectively grasp the various e-commerce situations in the society. If teachers absorb only $50 \%$ of the information in the society, the students absorb knowledge. $25 \%$, such a declining situation will lead students to lack effective control over the operation of the actual market. Although Internet technology makes information dissemination and sharing more convenient, the core competencies and methods in each company's operations are still relatively private. They are not easily accessible on the Internet or other channels and require real penetration into the company's interior. Perceived operations can only know the situation of internal operations. This kind of knowledge cannot be obtained through simple academic research. Although many teachers can gradually obtain comprehensive information afterwards, they do not have much reference for the moment. The completion of academic theories indicates that the field is very mature and development has been going on for a long time. This theory cannot Effective support for the handling of new issues. This situation does not mean that there is no meaning of teaching. At the theoretical level, it is still necessary to have a certain understanding of the past and to avoid the repetition of old problems. There is a shortage of "dual-qualified" teachers in teaching, and teachers with practical social practice skills may be relatively lacking in theory, and cannot effectively translate experience into teaching methods for students, or corporate staff will have guidance Reservations. Although school-enterprise cooperation has been launched, the supportive power of enterprises has been very small. Some corporate employees have more instructions in the working environment, and there are relatively few examples of flexible application practices and case studies. Students cannot have a more complete picture of the company's actual environment. In particular, many companies will use laws and regulations in their operations, and these practical skills will not be displayed in actual teaching. Even at the grass-roots level in many enterprises, there is no way to know how the middle-level and high-level companies operate in e-commerce. These enterprises' core competencies are part of the company's own retention and are not taught to students arbitrarily. In particular, students are more likely to retain their reservations when they are uncertain that they will become future participants in business operations.

\section{PRACTICAL TEACHING REFORM OF HIGHER VOCATIONAL E-COMMERCE MAJOR IN THE INTERNET PLUS BACKGROUND}

\section{A. Determine the clear goal of personnel training}

It is necessary to clearly set the talent training goals in light of the school's existing resource advantages. Although the general direction of talent cultivation is to enhance the professionalism of students, there are also many situations in professional competence, including the ability to execute basic business operations, operational management, and communication and coordination capabilities in e-commerce. Determined the training of the curriculum settings, the use of resources. We must make full use of the support from government resources, cooperation units, and enterprises so that talent training can be supported by more conditions. At the same time, the talent training design can be more in line with the actual situation, and schools can be more scientifically drawn up. We must pay attention to the depth of ability training and avoid trying to avoid it. We must pay attention to the internal optimization of the professional application ability and allow each professional training ability to be closely integrated with the actual situation to form a professional and systematic training. It is necessary to have a high degree of emphasis on practical training courses and optimize the training curriculum planning. Let all resources can be gathered to practical training, through the optimization of conditions to achieve training courses.

\section{B. Pay attention to the cooperation of high-quality school- enterprise cooperation}

Even to a certain extent, it is necessary to make a differential talent training plan based on the market situation, to make reliable and high-quality school-industry cooperation, to communicate the standards and goals of employing the enterprise, and to develop customized talents for the needs of the enterprise. It has close contact and communication with enterprises, truly grasps the needs of employing people, understands the changes in the demand for talent on the market, and improves the advanced nature of teaching and training. Can be set up more specialized e-commerce professional courses, so that students comprehensive application capabilities have been improved. To optimize cooperative enterprises, we must do a good job in enterprise research, know the actual operating conditions of enterprises, and carry out more schoolindustry cooperation and communication every day so that enterprise personnel can communicate with the school. Allowing enterprise talents to come to the school regularly for training and instruction may be the human resources department, technical department, product research department, etc. of the company, allowing students to understand the various aspects of the e-commerce operation environment and increase the actual value of teaching. Can make more use of the advantages of the actual situation of enterprises and schools, so that companies provide more support to help schools cultivate talent, while allowing talent to feed back the operation of 
enterprises, to ensure that the basic talent needs of enterprises. Improve the bonding and loyalty between students and businesses. In the course of school, students should be trained in the awareness and ability of students in all aspects, so that they can become more familiar with and recognize the corporate culture, thereby effectively improving the matching of talents. Schools can also carry out internal corporate training work to help companies do a good job of on-the-job training for employees, on-the-job training based on other training management work, and effectively increase the viscosity between schools.

\section{Optimization of teacher resources}

It is possible to pool more high-quality teacher resources in the society as a part-time lecturer in the school. Through the advantages of each lecturer, short-term lectures are given to enrich the course content and make it practical, especially for those who are engaged in related professions in many societies. , Will be more willing to use part-time methods, on the one hand to impart their own essence, transform their personal value, on the other hand, the school has improved the quality of course teaching. The part-time classes of practitioners in the society can, to a certain extent, make up for the lack of practical experience of traditional university academic academic teachers. The school teachers' resources also need to be fully utilized, and teachers' professional training assessments should be done. They should provide opportunities for teachers to get access to the actual business operations, and at the same time absorb the experience of the relevant management personnel of the company. Schools can provide teachers with professional on-campus training or off-campus practice activities. They can also use online training to understand the status of the social market and enhance professionalism. The full-time teacher of colleges and universities should exercise more enterprises. At least one or two months each year, they should go to relevant companies to perform job training. They must also learn the latest professional conditions and learn the latest professional skills so that they can better carry out practical training after returning to school.

\section{Encourage students to practice}

The operation of e-commerce has become more common. As a practical application of ability training, students can be encouraged to open their own shop to enhance their own practical experience. The accumulation of these practical abilities can be encouraged by the use of credits and other systems, and outstanding individuals can even receive a variety of other school awards to enhance their motivation and effectiveness. At the same time, we can recommend other companies' daily part-time work so that students can adapt to changes in society. When they graduate, they are able to effectively cope with actual work needs and optimize their professional skills. It can even encourage teamwork among students, simulate the teamwork atmosphere in real shop operations, and give full play to their respective strengths, so that students can develop the necessary teamwork skills and awareness before entering the social workplace. In the team, students can understand each other's coordination and communication skills, understand the interests of the team first, give full play to their advantages and characteristics, and establish self-confidence in practice. Learning through a variety of competition activities to motivate students to carry out practical activities, and even conduct e-commerce operation and creative competition, so that students with the same interest in the school team together to stimulate creativity, through the integration of resources to effectively help students achieve their own growing up. Teachers and students need to actively pay attention to practical training, expand the form and content of practical training, and avoid the limitations of teaching. Teachers and students should communicate interactively and fully develop thinking to help students better self-inquiry and study. Daily class meetings and exchanges will be carried out to allow students to exchange ideas about their own experiences of practical participation. Teachers can also make necessary guidance so that students without social experience can have stronger practical adaptability. Encourage students to use short-term internships in related businesses during winter and summer vacations. Not only can they learn a lot of professional knowledge, but they can also acquire a lot of practical skills.

\section{CONCLUSION}

The e-commerce professional education under the internet plus environment has a wide range of practical experience. It requires the school to carry out scientific and standardized planning for practical training, and concentrates resources on various aspects to provide students with a better environment for practical training and learning. It can mobilize all forces to match teaching with the actual market environment and improve the effectiveness of teaching. Let professional teaching be implemented in practice, fully integrate theory and practice, and improve vocational students' practical market competitiveness.

\section{REFERENCES}

[1] Wang Zhiqiang. Reform and Practice of Practical Training Teaching in Higher Vocational E-commerce Based on Vocational Skills Competition [J]. Economic and Trade Practice, 2017, (2): 139,141.

[2] Zheng Jinsheng, Xu Jing. Study on Modular Teaching of Higher Vocational E-commerce Professional Training under the Mode of School-enterprise Cooperation [J]. Vocational Education Forum, 2017, (9): 85-89.

[3] Yang Song. Microblog user network architecture research based on social network analysis [J]. Computer Science, 2014(41):204-207

[4] Li Yan, Wei Li. Analysis of the Teaching Path of E-commerce Professional Training in Higher Vocational Colleges Based on SchoolEnterprise Cooperation[J]. Journal of Qiqihar Teachers College, 2017, (3):108-110

[5] Wang Guangjing, Zhang Lei. Discussion on the Training Mode of Ecommerce Professionals in Special Vocational Colleges [J]. Modern Special Education, 2016, (10):79-80. 